\title{
1 Sustainable aquaculture through the One Health lens
}

2

3

4

5

6

7

8

Stentiford, G.D. ${ }^{* 1,2}$, Bateman, I.J. ${ }^{3}$, Hinchliffe, S. ${ }^{2,4}$, Bass, D. ${ }^{1,2}$, Hartnell, R. ${ }^{6}$, Santos, E.M. ${ }^{2,5}$., Devlin, M. ${ }^{7}$, Feist, S.W. ${ }^{1}$, Taylor, N. ${ }^{1,2}$, Verner-Jeffreys, D. ${ }^{1,2}$, van Aerle, R. ${ }^{1,2}$, Peeler, E.J. ${ }^{1,2}$, Higman, W.A. ${ }^{1}$, Smith, L. ${ }^{1}$, Baines, R. ${ }^{1}$, Behringer, D. ${ }^{8,9}$, Katsiadaki, I. ${ }^{1,2}$, Froehlich, H.E. ${ }^{10,11}$, Tyler, C.R. ${ }^{2,5}$

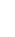

${ }^{1}$ International Centre of Excellence for Aquatic Animal Health, Centre for Environment, Fisheries and Aquaculture Science (Cefas), Weymouth Laboratory, Barrack Road, Weymouth, Dorset DT4 8UB, UK. ${ }^{2}$ Centre for Sustainable Aquaculture Futures, Geoffrey Pope Building, University of Exeter, Stocker Road, Exeter, EX4 4QD, UK.

${ }^{3}$ Land, Environment, Economics and Policy Institute, Xfi Building, University of Exeter, Rennes Drive, Exeter, Devon, EX4 4PU, UK.

${ }^{4}$ Department of Geography, University of Exeter, Amory Building, Rennes Drive, Exeter, EX4 4RJ, UK. ${ }^{5}$ Biosciences, University of Exeter, Geoffrey Pope Building, Stocker Road, Exeter, EX4 4QD, UK. ${ }^{6}$ International Centre of Excellence for Seafood Safety, Centre for Environment, Fisheries and Aquaculture Science (Cefas), Weymouth Laboratory, Barrack Road, Weymouth, Dorset DT4 8UB, UK. ${ }^{7}$ Environment and People Theme, Centre for Environment, Fisheries and Aquaculture Science (Cefas), Lowestoft Laboratory, Lowestoft NR33 OHT, UK.

${ }^{8}$ Fisheries and Aquatic Sciences, University of Florida, 7922 NW 71st Street, Gainesville, FL 32653, USA.

${ }^{9}$ Emerging Pathogens Institute, University of Florida, Gainesville, FL, USA.

${ }^{10}$ Department of Ecology, Evolution, and Marine Biology, University of California, Santa Barbara, Santa Barbara, CA, USA.

${ }^{11}$ Environmental Studies, University of California, Santa Barbara, Santa Barbara, CA, USA.

\section{*Correspondence: grant.stentiford@cefas.co.uk}

Twitter: @grantstentiford 


\section{Abstract}

Aquaculture is predicted to supply the majority of aquatic dietary protein by 2050 . For aquaculture to deliver significantly enhanced volumes of food in a sustainable manner, appropriate account needs to be taken of its impacts on environmental integrity, farmed organism health and welfare and human health. Here, we explore increased aquaculture production through the One Health lens and define a set of success metrics - underpinned by evidence, policy and legislation - that must be embedded into aquaculture sustainability. We provide a framework for defining, monitoring and averting potential negative impacts of enhanced production - and consider interactions with landbased food systems. These metrics will inform national and international science and policy strategies to support improved aquatic food system design.

\section{MAIN}

Aquaculture is one of the fastest growing and highly traded food sectors globally - Asia accounts for 90\% of production [1] and volumes are predicted to double by 2050 [1] (Supplement 1). Enhanced sustainable production (ESP) in aquaculture features within the Rome Declaration of the $2^{\text {nd }}$ International Conference on Nutrition (ICN2), the United Nations Framework Convention on Climate Change (COP21) and in the 2030 Agenda for Sustainable Development [2]. Achieving ESP is technically, socially and politically complex: the sector spans small homestead-scale production systems - underpinning food security in rural settings in low- and middle-income counties (LMICS) to medium sized farms that contribute to exports and high-technology industrial-scale production of globally traded products. More than 500 aquatic species are farmed in widely divergent social and legislative infrastructures - with different end goals. Thus, a holistic approach to the design and implementation of aquaculture systems is needed [3] - framed within the broader context of sustainable food systems [4].

The sector offers many positive aspects: poverty alleviation in some of the lowest income regions [5], production increases from technological advances and selected species lines[6], the use of non-fed (e.g. molluscs) and extractive species (e.g. seaweed) [7] with benefits of farms for proximate marine biodiversity [8], comparatively lower environmental impact of some types of aquaculture $[9,10]$ and smaller spatial footprints compared with both capture fisheries $[11,12]$ and land-based agriculture [13]. However, numerous sustainability challenges must be addressed across the diverse range of aquaculture sectors. For example, economic gains in the global shrimp sector have been prioritised in spite of evidence of major mangrove forest degradation [14], bonded labour and social inequities [15], and potentially high carbon footprints $[16,17]$. The profitable northern hemisphere Atlantic 
salmon aquaculture industry farms native stocks but claims of subsequent pathogen spill over [18], loss of genetic integrity of native populations [19] and wider environmental degradation of sensitive habitats [20] persist. Similarly, antibiotic overuse in southern hemisphere Atlantic salmon production [21] remains disproportionate to the economic benefits in otherwise deprived rural communities [22]. The principles of One Health - defined as the collaborative, multi-sectoral, and transdisciplinary approach to achieving beneficial health and well-being outcomes for people, non-human organisms and their shared environment (Supplement 2) - offers a practical framework to achieve aquaculture ESP. Governments, producers, wider industry, scientists and the public must engage to facilitate the design of food systems to decouple the human health benefits of consuming aquatic protein from negative environmental, organismal and societal impacts that may develop around a rapidly expanding, unregulated sector. Interaction and integration of independent accreditation schemes, like the 'Best Aquaculture Practice' standards https://www.bapcertification.org/, with traditional governmental regulation could deliver greater positive impacts [23].

Here, we propose a practical means to implement the One Health approach to aquaculture ESP within national and international policy, legislation, evidence provision and research (Figure 1), that can be tailored to industry sub-sectors to address specific sustainability requirements.

\section{Success metrics}

Sustainability measures must be rigorously applied across all food sectors if aquaculture is to become part of regional and global sustainable food systems. Evidence-based success metrics indicate producers', co-operatives', sub-sectors', or the regional industry's compliance with One Health principles (Table 1, Figure 2) and aid metric-specific policy and legislation development. Metrics that are fully achieved gain the highest score of 5, corresponding to policy and legislation being in place and consistently applied. The lowest score of 1 is given for unsuccessful metrics when no supporting research or evidence is in place to support policy and legislative design. This approach allows tailored sub-sector evaluation, highlighting specific areas for improvement and directing future research and evidence to support design of policy and legislation (Figure 3).

\section{Human health.}

Aquaculture can provide a range of public health, economic and social benefits. The One Health approach might result in a series of decisions on investment and health quality that make 'optimisation' closer to a set of trade-offs between economic gain and productivity, animal welfare or system-wide health. Market preferences or social aspirations to sponsor or tolerate certain levels 
of health will become crucial in establishing practical health. In Bangladesh, for example, finfish consumption increased by $150 \%$ between $2000-2010$, while adjusted prices for cultured catfish and tilapia fell by $40 \%$ - largely as a result of expanding freshwater pond production [24] - with considerable impact on human health and wellbeing [25]. Simultaneously, rapidly urbanising populations can suffer from the co-existence of food poverty and over-consumption of processed foods [26] - aquaculture products could alleviate some of these issues. While producers may choose more profitable and sometimes less nutritious cash- and export-oriented crops, aquaculture as a component of polyculture traditions in many LMICs can contribute to the local availability of nutritious products. An estimated 20 million people are directly employed in aquaculture worldwide, mostly in Asia, while supporting industries and services contribute to 100 million jobs globally. Trade, meaningful employment, gender equity, increasing rural production (which further benefits rural schooling), diet and infrastructure can be included in human success metrics. Early evaluation of public health risks is fundamental within the principles of One Health. For example, whilst the perceived increased GDP gains from international trade have driven rapid growth in bivalve mollusc production since the 1950s, a systemic absence of mature legal frameworks; robust data on origin, prevalence and levels of putative human pathogens in aquatic systems; and scarce expertise at the food business operator or official services level have underestimated hazards and severely impacted value chains, limiting exports for many LMICs [1].

Between 70 to $80 \%$ of production is undertaken by a "missing or squeezed middle" of commercial producers [27] who "enjoy none of the benefits of investments in biosecurity or pathogen control characteristic of intensive systems nor, the low input/low risk/low output typical of extensive systems" [28]. These producers are adopting practices such as commercial feed use, water and livestock treatments, but are also loosely tied to value chains, subject to little or no veterinary oversight and are weakly regulated by buyer and/or state organisations. Disease is a persistent threat - constituting an estimated $\$ 6 \mathrm{bn}$ loss per annum in the global industry [29] - meaning these producers will be key in improving health outcomes globally. Developing accreditation and consumer trust can be a challenge, particularly as production starts to shift from a bipolar South-North export model (with relatively well-developed buyer driver governance) to a trade pattern that is increasingly South-South with growing production for domestic markets [30]. Enhancing animal and environmental health requires a programme of engagement with producers to develop ownership of and compliance with ESP goals. The burden of risk and rewards are unevenly distributed within many aquaculture value chains, providing disincentives for innovative and sustainable practices - equitable value chains and rewards for sustainable production will be fundamental to achieve ESP. We outline 
five success metrics for the human health component of a One Health approach to aquaculture ESP (Table 1 and Figure 2).

\section{Organism health.}

Production occurs within complex ecological systems physically embedded within an environment differing from the farmed species' wild habitat. Farmed animals or plants interact with communities of viruses, bacteria, small eukaryotes, and other animals and plants within the aquaculture system. Microbes within the system include known and unknown pathogens with potential to cause infection and disease in farmed species. Crop-growing ponds are highly modified, 'artificial' ecosystems that can unintentionally create an environment for rapid pathogen propagation and epidemic disease outbreaks - and have been a source of many emergent diseases. For example, the incidentally discovered microsporidian Enterocytozoon hepatopenaei (EHP) found at low levels in a pond in Thailand over 10 years ago is now one of the most widespread and impactful pathogens in shrimp aquaculture [31]. Thus, stock management must be considered in terms of health and disease manifestation, zoonoses, biosecurity, genetics, and treatments' or interventions' impact on the local environment.

Creating growing conditions conducive to high stock health and welfare is critical for aquaculture ESP - perhaps the most important barrier to development of the industry to 2050 [29]. Profiling microbial hazards, even in a preventative manner, utilising emergent technologies such as high throughput sequencing of water, sediment, feed and host tissues is increasingly an option [32]. These technologies can also identify broad biosecurity risks that aquaculture farms pose to the surrounding environment. Preventing pathogen spillover to the environment and wildlife, and viceversa, is a critical measure that must be built into aquaculture systems.

Aquaculture feeds alter the ecology of aquaculture systems and can introduce other compounds such as antimicrobial residues (AMR), which potentially influence stock health and the physicochemical properties of the system. Feeds range from natural pond fertilisers to formulaic feeds for enhancing stock performance. Pharmaceuticals, liming or sterilisation between cropping cycles and biocides can create favourable conditions for disease development by eutrophication, leading to hypoxic stress, or by environmental dysbiosis, whereby disease agents may be preferentially selected and become pathogenic for resident hosts [33]. Chemical spill-over into the surrounding environment, to other farmed stock, wildlife and humans via zoonotic diseases and antimicrobial 
residues must be prevented in future One Health design of aquaculture systems. AMR genetic elements within aquaculture systems is of great concern largely due to the intensive and often inappropriate use of antibiotics to treat disease. While some aquaculture sub-sectors, like Norwegian salmon, are exemplars of antibiotic use reduction, other sub-sectors require substantial improvement [34].

Farmed species choice selection can be determined by their capacity for their maintenance with minimal ecological modification to the farm environment and a low potential to impact the surrounding environment. While the benefits of sourcing seed stock from natural environments may encourage propensity for disease in captive settings [29]; conversely, the use of specific pathogenfree (SPF) stock may not always be an appropriate choice, particularly when animals are stocked into open systems in which a native microbial community may rapidly exploit microbiologically-naïve hosts [35]. Genetic structuring at farm population level must aim to reduce the likelihood of disease epidemics and create resilience to challenges encountered within and between cropping cycles. Mixed species or multi-trophic culture systems can be considered for managing health of other stock, minimizing environmental impact and may be more ecologically stable and resilient than monocultures [36]. Introducing non-native, invasive species to the local environment should be avoided to prevent the risk of hybridisation and genetic introgression with native species, and the introduction of pathogen spillover [37].

Close attention to national and transboundary spread of hazards - particularly via trade - must extend beyond live animals and include the risk of distributing pathogens via end-products, even those destined directly for human consumption that would not normally interact further with the environment [38]. The organism health component of a One Health approach are outlined by five broad success metrics (Table 1 and Figure 2).

\section{Environmental health.}

Sixty-three-percent of aquaculture occurs in fresh waters, with $29 \%$ in marine and $8 \%$ in brackish habitats [39] - relatively similar projections are expected in future production (Supplement 1). Aquaculture ESP is constrained by the amount and quality of freshwater available. Inland aquaculture globally withdraws around $429 \mathrm{~km}^{3}$ freshwater per year, representing $3.6 \%$ of Earth's surface flowing water [40]. Future freshwater demands must be balanced against other needs, including for land-based agriculture that currently uses $70 \%$ of the readily accessible supply [40]. The IPCC report (The Ocean and Cryosphere in a Changing Climate, 2019) indicated that climate change 
will result in warming seas and the expansions of hypoxic zones, affecting where marine aquaculture may operate and which species can be farmed [41]. Climate models indicate many tropical regions of the world - where most aquaculture takes place - will become hotter and drier, which will likely limit available freshwater supply and influence which species can farmed in those environments [42]. In contrast, temperate regions may be expected to become warmer and wetter, potentially opening new aquaculture development opportunities. Up to $60 \%$ of water withdrawn for inland aquaculture could be re-used with adequate pollution control measures for purification of effluents, re-use of nutrients and control of percolation losses [39]. Highest production to 2030 and beyond will occur in freshwater systems in Asia [1]. Sustainable management of pollution and effluent discharge is essential; special attention must be given to sub-regions where little or no freshwater operational control measures exist. Freshwater ecosystems are especially vulnerable to biodiversity impacts $35 \%$ of freshwater fish are classified as vulnerable or threatened [43], which are vital for providing feed, broodstock, seed (eggs/larvae/fry) and genetic resources for many farmed species.

Although all aquaculture animals are ectotherms, some forms of aquaculture currently operate with a relatively high carbon footprint. For example, shrimp produced on land formerly occupied by mangroves has a carbon footprint of $1603 \mathrm{~kg} \mathrm{CO}_{2}$ per $\mathrm{kg}$ of shrimp produced - a figure similar to production of beef (1440 $\mathrm{kg} \mathrm{CO}_{2} ;$ [44]). Feed inputs are a major environmental and economic cost for many species in aquaculture - an estimated $15.6 \mathrm{~m}$ tonnes of wild fish harvested globally are used in the production of fish meal and fish oils (FMFO), almost half of which is used in aquaculture feed [45]. Alternative feeds, including those based on insect, plant or algal proteins show promise [46] but are yet to offer consistent replacement of FMFO-based feeds. The comparative efficiency at converting protein and energy from feed sources and toleration of species such as carp and tilapia to challenging physico-chemical environments have led to significant expansion in global production of these species [1], demonstrating their potential for future aquaculture ESP. Similarly, extractive, nonfed species like filter-feeding bivalves, algal grazers, detritivores and autotrophic plants (mainly macroalgae) are considered some of the lowest impact aquaculture organisms (Supplement 1). Culture platforms for seaweeds and bivalves can simultaneously act as nurseries for native biodiversity and boost productivity of wild fisheries, while helping to control nutrient and microbial levels in the water column [8]. Alternatively, the contained nature of onshore recirculating aquaculture systems (RAS) hold potential for greater environmental control, better biosecurity and a smaller environmental footprint in terms of land space and water use compared to open systems, particularly when aligned with terrestrial food and energy systems [47]. 
Land space allocation for future aquaculture must be mindful of the impacts on biodiversity and natural resource productivity. Globally, approximately $8.7 \mathrm{~m}$ hectares is used for freshwater aquaculture production and a further $2.3 \mathrm{~m}$ hectares for brackish water production [39]. Future inland aquaculture will likely compete for space with terrestrial agriculture, which occupies more than one third - or 5 bn hectares - of the Earth's surface [48]. Open oceans provide ample space but offshore systems present considerable operational challenges more suited to larger industry operations. Nevertheless, current US seafood consumption could be met by extending offshore marine aquaculture into less than 1\% of Exclusive Economic Zones belonging to coastal states [49]. Lessons must be learned from the detrimental environmental effects of mangrove removal for shrimp aquaculture - countries like Bangladesh have destroyed nursery grounds for important commercial wild fisheries and rendered large tracks of land unsuitable for agriculture due to the resulting saltwater intrusion [50]. Finally, aquaculture ESP must consider areas of cultural and (inter)national heritage importance and must not impose on areas of outstanding natural beauty. The environment component of a One Health approach to aquaculture ESP are outlined in five metrics (Table 1 and Figure 2).

Interactions between success metrics. The success metrics presented here comprise a research, evidence, policy and legislative package which can guide governing bodies' aquatic food strategies. Importantly, aquaculture production must not be considered in isolation but rather as a food system with intricate linkages to wild capture fisheries and terrestrial agriculture systems [9]. Individual metrics will benefit aquaculture ESP, but it is the interactions and dependencies between individual metrics that may have the greatest capacity to elicit positive change. Conversely, interactions may elicit unforeseen negative feedback loops, which must be guarded against. Such examples include metrics Organism SM2, Organism SM3 and Organism SM4 (Table 1 and Figure 2): policy and legislation promoting farm biosecurity can reduce chemical, AMR and zoonotic hazards from entering the environment. Environment SM3, Environment SM5 and People SM4 (Table 1 and Figure 2) interact where lowering the spatial footprint of aquaculture has positive impacts on protecting biodiversity, optimising water quality and providing people with quality employment. However, if a metric is perceived as requiring excessive regulation, counterproductive actions may be taken by stakeholders to evade the metric, thereby negating its intended impact.

\section{Future directions} [51] and broader targets from the Sustainable Development Goals (SDGs) [52]. The extension of the 
One Health approach beyond zoonotic diseases - to address grand societal challenges like food security - was proposed in programs like the Network for Evaluation of One Health [see Supplement

2). Our approach enables national policies to collectively contribute to aquaculture ESP.

Data collection for monitoring success metrics will require interaction across government departments and a broad range of aquaculture stakeholders. Accountability must extend beyond national borders, particularly where high-income countries obtain food from medium to low-income and/or less stable regions at the cost of those ecosystems and people [53]. Given seafood is one of the most traded commodities [54], the unaccounted burdens of international, unsustainable socioecological practices require attention within the aquaculture sector - and seafood in general. Success metric achievement at national levels, coupled with international cooperation, forms the cornerstone of widespread One Health adoption.

Aquaculture can mitigate negative impacts associated with land-based food production systems particularly where land-and water-based systems are integrated - to protect terrestrial habitats from the impact associated with some current farming systems $[55,56]$. One Health principles will facilitate increasing production of aquaculture species with efficient food production and sustainable environmental footprints - while supporting local socio-economic needs. If put into practice, the success metrics presented here serve as an example for the design and assessment of not just aquaculture, but whole food systems

\section{References}

[1] FAO. The State of World Fisheries and Aquaculture 2018 - Meeting the sustainable development goals. Food and Agriculture Organization of the UN (FAO), Rome, Italy. Licence: CC BY-NC-SA 3.0 IGO (2018).

[2] FAO. Fishery and Aquaculture Statistics Yearbook 2016. Rome 104p. (2016).

[3] Stead, S. M. Using systems thinking and open innovation to strengthen aquaculture policy for the United Nations Sustainable Development Goals. J. Fish Biol. 94, 837-844. https://doi.org/10.1111/jfb.13970 (2018).

[4] Berry, E.M., Dernini, S., Burlingame, B., Meybeck, A., Conforti, P. Food security and sustainability: can one exist without the other? Publ. Health Nutr. 18, 2293-2302. doi:10.1017/S136898001500021X (2014).

[5] De Silva S. S., Davy F. B. Aquaculture successes in Asia: contributing to sustained development and poverty alleviation. In: De Silva S.S., Davy F.B. (eds) Success Stories in Asian Aquaculture. Springer, Dordrecht. doi.org/10.1007/978-90-481-3087-0_1 (2010).

[6] Midtlyng, P. J., Grave, K. and Horsberg, T. E. What has been done to minimize the use of antibacterial and antiparasitic drugs in Norwegian aquaculture? Aquacult. Res. 42, 28-34 doi:10.1111/j.13652109.2010.02726.x (2011).

[7] Carboni, S. et al. Mussel consumption as a "food first" approach to improve omega-3 status. Nutrients 11, e1381. doi: 10.3390/nu11061381, 1381 (2019).

[8] Gentry, R. R. et al. Exploring the potential for marine aquaculture to contribute to ecosystem services. Rev. Aquacult. doi:10.1111/raq.12328 (2019).

[9] Hilborn, R., Banobi, J., Hall, S. J., Pucylowski, T., Walsworth, T. E. The environmental cost of animal source foods. Front. Ecol. Environ. 16, 329- 335. doi:10.1002/fee.1822 (2018). 
[10] Poore, J., Nemecek, T. Reducing food's environmental impacts through producers and consumers. Science 360, 987-992 (2018).

[11] Jennings, S. Aquatic food security: trends, challenges and solutions for a single nation embedded in a dynamic global web of producers, processors and markets. Fish Fisher. DOI: 10.1111/faf.12152 (2016).

[12] Lester, S. E., Gentry, R. R., Kappel, C. V., White, C., Gaines, S. D. Offshore aquaculture in the United States: untapped potential in need of smart policy. Proc. Nat. Acad. Sci. 115. Doi: 10.1073/pnas.1808737115 (2018).

[13] Froehlich, H. E., Runge, C. A., Gentry, R. R., Gaines, S. D., Halpern, B. S. Comparative terrestrial feed and land use of an aquaculture-dominant world. Proc. Nat. Acad. Sci. 201801692 doi.org/10.1073/pnas.1801692115 (2018).

[14] de Graaf, G., Xuan, T. Extensive shrimp farming, mangrove clearance and marine fisheries in the southern provinces of Vietnam. Mangroves and Salt Marshes 2, 159 doi.org/10.1023/A:1009975210487 (1998).

[15] Nakamura, K. et al. Seeing slavery in seafood supply chains. Sci. Advan. 4, e1701833 (2018).

[16] Kauffman, J.B. et al. The jumbo carbon footprint of a shrimp: carbon losses from mangrove deforestation. Front. Ecol. Environ. 15, 183-88 (2017).

[17] Henriksson, P.J.G., Järviö, N., Jonell, M., Guinée, J.B., Troell, M. The devil is in the details - the carbon footprint of a shrimp. Front. Ecol. Environ. 16, 10-11. doi.org/10.1002/fee.1748 (2018).

[18] Price, M. H. H. et al. Sea louse infection of juvenile sockeye salmon in relation to marine salmon farms on Canada's west coast. PLoS ONE 6, e16851 (2011).

[19] Crego-Prieto, V. et al. Aquaculture and the spread of introduced mussel genes in British Columbia. Biol. Invasions 17 doi.org/10.1007/s10530-015-0853-z (2015).

[20] Sugiura, S. H. Phosphorus, aquaculture, and the environment. Rev. Fish. Sci. Aqua. 26, 515-521, DOI: 10.1080/23308249.2018.1471040 (2018).

[21] Higuera-Llantén, S. et al. Extended antibiotic treatment in salmon farms select multiresistant gut bacteria with a high prevalence of antibiotic resistance genes. PLOS ONE 13, e0203641 (2018).

[22] Ceballos, A., Dresdner-Cid, J. D., Quiroga-Suazo, M. A. Does the location of salmon farms contribute to the reduction of poverty in remote coastal areas? An impact assessment using a Chilean case study. Food Policy 75, 68-79. doi.org/10.1016/j.foodpol.2018.01.009 (2018).

[23] Vince, J., Haward, M. Hybrid governance in aquaculture: Certification schemes and third party accreditation.

[24] Toufique K. A., Belton, B. Is Aquaculture pro-poor? Empirical evidence of impacts on fish consumption in Bangladesh. World Dev. 64, 609-620 (2014).

[25] Toufique, K. A., Farook, S., Belton, B. Managing fisheries for food security: implications from demand analysis. Mar. Resour. Econ. 33, doi: 10.1086/694792 (2017).

[26] GBD. Diet Collaborators. Health effects of dietary risks in 195 countries, 1990-2017: a systematic analysis for the Global Burden of Disease Study 2017. The Lancet doi: 10.1016/S0140-6736(19)30041-8 (2019).

[27] Ricciardi, V., Ramankutty, N., Mehrabi, Z., Jarvis, L., Chookolingo, B. How much of the world's food do smallholders produce?. Glob. Food Sec. 17, 64-72 (2018).

[28] Little, D. C. et al. Sustainable intensification of aquaculture value chains between Asia and Europe: A framework for understanding impacts and challenges. Aquaculture 493, 338-354 (2018).

[29] Stentiford, G.D. et al. New paradigms to solve the global aquaculture disease crisis. PLoS Path. 13: e1006160 (2017).

[30] Belton, B., Bush, S. R., Little, D. C. Not just for the wealthy: Rethinking farmed fish consumption in the Global South. Glob. Food Sec. 16, 85-92 (2018).

[31] Stentiford, G. D., Bass, D., Williams, B. A. P. Ultimate opportunists - the emergent Enterocytozoon group microsporidia. PLoS Path. 15, e1007668. https://doi.org/10.1371/journal.ppat.1007668 (2019).

[32] Bass, D., Stentiford, G.D., Wang, H-C., Koskella, B., Tyler, C. (2019). The Pathobiome in animal and plant diseases. Trends in Ecology and Evolution https://doi.org/10.1016/j.tree.2019.07.012

[33] Egan, S., Gardiner, M. Microbial dysbiosis: rethinking disease in marine ecosystems. Front. Microbiol. 7, 991 (2016).

[34] Henriksson, P.J.G. et al. Unpacking factors influencing antimicrobial use in global aquaculture and their implication for management: a review from a systems perspective. Sustain. Sci. 13, 1105-1120 (2018).

[35] Alday-Sanz, V. et al. Facts, truths and myths about SPF shrimp in Aquaculture. Rev. Aquacult. doi:10.1111/raq.12305 (2018).

[36] Ying, C. et al. The effects of marine farm-scale sequentially integrated multi-trophic aquaculture systems on microbial community composition, prevalence of sulfonamide-resistant bacteria and sulfonamide resistance gene sul1. Sci. Total Environ. 643, 681-691 doi: 10.1016/j.scitotenv.2018.06.204. (2018). 
[37] Peeler, E.J., Taylor, N.G. The application of epidemiology in aquatic animal health -opportunities and challenges. Vet. Res. 42, 94 doi:10.1186/1297-9716-42-94 (2011).

[38] Oidtmann, B., Stentiford, G. D. White spot syndrome virus (WSSV) concentrations in crustacean tissues - a review of data relevant to assess the risk associated with commodity trade. Transbound. Emerg. Dis. 58, 469-482 (2011).

[39] Ottingera, M., Claussa, K., Kuenzerb, C. Aquaculture: Relevance, distribution, impacts and spatial assessments- A review. Ocean Coast. Managem. 119, 244-266 (2016).

[40] Verdegem, M. C. L., Bosma, R. H. Water withdrawal for brackish and inland aquaculture, and options to produce more fish in ponds with present water use. Water Policy 11(S1), 52-68 (2009).

[41] IPCC. Special Report on the Ocean and Cryosphere in a Changing Climate (2019) https://www.ipcc.ch/srocc/home/ (2019).

[42] Fu, R. Global warming-accelerated drying in the tropics. Proc. Nat. Acad. Sci. 24, 112: 3593-3594 (2015).

[43] WWF. Living Planet Report - 2018: Aiming Higher. By: Grooten, M. Almond, R. E. A. (Eds). WWF, Gland, Switzerland (2018).

[44] Kauffman, J. B. et al. The jumbo carbon footprint of a shrimp: carbon losses from mangrove deforestation. Front. Ecol. Environ. 15, 183-88 (2017).

[45] Halpern, B.J. et al. Putting all foods on the same table: achieving sustainable food systems requires full accounting. Proc. Nat. Acad. Sci. 116, 18152-56 https://doi.org/10.1073/pnas.1913308116 (2019).

[46] Cottrell, R.S., Blanchard, J.L., Halpern, B.S. et al. Global adoption of novel aquaculture feeds could substantially reduce forage fish demand by 2030. Nat Food 1, 301-308 (2020). https://doi.org/10.1038/s43016-020-0078-x

[47] Badiola, M., Mendiola, D., Bostock, J. Recirculating Aquaculture Systems (RAS) analysis: Main issues on management and future challenges. Aquacult. Engineer. 51, 26-35 (2012).

[48] Ramankutty, N. et al. Trends in global agricultural land use: implications for environmental health and food security. Ann. Rev. Plant Biol. 69, 789-815 (2018).

[49] Gentry, R. R. et al. Mapping the global potential for marine aquaculture. Nat. Ecol. Evol. 1, 1317-1324 doi:10.1038/s41559-017-0257-9 (2017).

[50] Hossain, M., Hasan, M. R. An assessment of impacts from shrimp aquaculture in Bangladesh and prospects for improvement (FAO Publication; ISBN 978-92-5-130007-7) http://www.fao.org/3/a-i8064e.pdf (2017)

[51] Brugère, C., Aguilar-Manjarrez, J., Beveridge, M. C. M., Soto, D. The ecosystem approach to aquaculture 10 years on - a critical review and consideration of its future role in blue growth. Rev. Aquacult. 11, $493-514$. doi.org/10.1111/raq.12242 (2019).

[52] Hambrey, J. The 2030 Agenda and the Sustainable Development Goals: The Challenge for Aquaculture Development and Management. FAO Fisheries and Aquaculture Circular; Rome, no. C1141: I, IV, VII, 1-62 (2017).

[53] Hicks, C.C. et al. Harnessing global fisheries to tackle micronutrient deficiencies. Nature 574, $95-96$ (2019).

[54] Gephart, J. A., Pace, M. L Structure and evolution of the global seafood trade network. Environm. Res. Lett. 10, 125014. https://doi.org/10.1088/1748-9326/10/12/125014 (2015).

[55] Lamb, A. et al. The potential for land sparing to offset greenhouse gas emissions from agriculture, Nat. Clim. Change 6, 488-492 doi:10.1038/nclimate2910 [2016].

[56] Pretty, J. et al. Policy challenges and priorities for internalizing the externalities of modern agriculture. J. Environm. Plan. Manag. 44, 263-283 DOI: 10.1080/09640560123782 (2001). 


\section{Acknowledgements}

415 We acknowledge the Centre for Sustainable Aquaculture Futures (a collaboration between the 416 Centre for Environment, Fisheries and Aquaculture Science and the University of Exeter) for funding 417 under contract Cefas Seedcorn contract \#SP003 to host a workshop 'Sustainable Aquaculture 418 through the One Health Lens' at the Department for Environment, Food and Rural Affairs (Defra) 419 London, on $1^{\text {st }}$ July 2019. The input to that workshop by colleagues from across Defra provided 420 significant guidance for the material contained within this article.

\section{Author Contributions}

423 G.D.S. conceptualised the manuscript and led the development of the text, I.J.B, S.H., D.B., R.H. 424 E.M.S., M.D., S.W.F., N.T., D.V.J., R.V-A., E.J.P., W.A.H., L.S., R.B., I.K. and C.R.T. attended and 425 presented at the 'Sustainable Aquaculture through the One Health lens' workshop in London on July $4261^{\text {st }} 2019$ and wrote elements of this manuscript. D.B. and H.E.F. wrote elements of the manuscript 427 and were involved with wide ranging discussions on integration of One Health principles within 428 aquaculture and sustainable food system design.

\section{Competing Interests}

431 The authors declare no competing interests

\section{Supplementary Information}

434 SUPPLEMENT 1 - GLOBAL AQUACULTURE (sections A and B)

435 SUPPLEMENT 2 - ONE HEALTH 


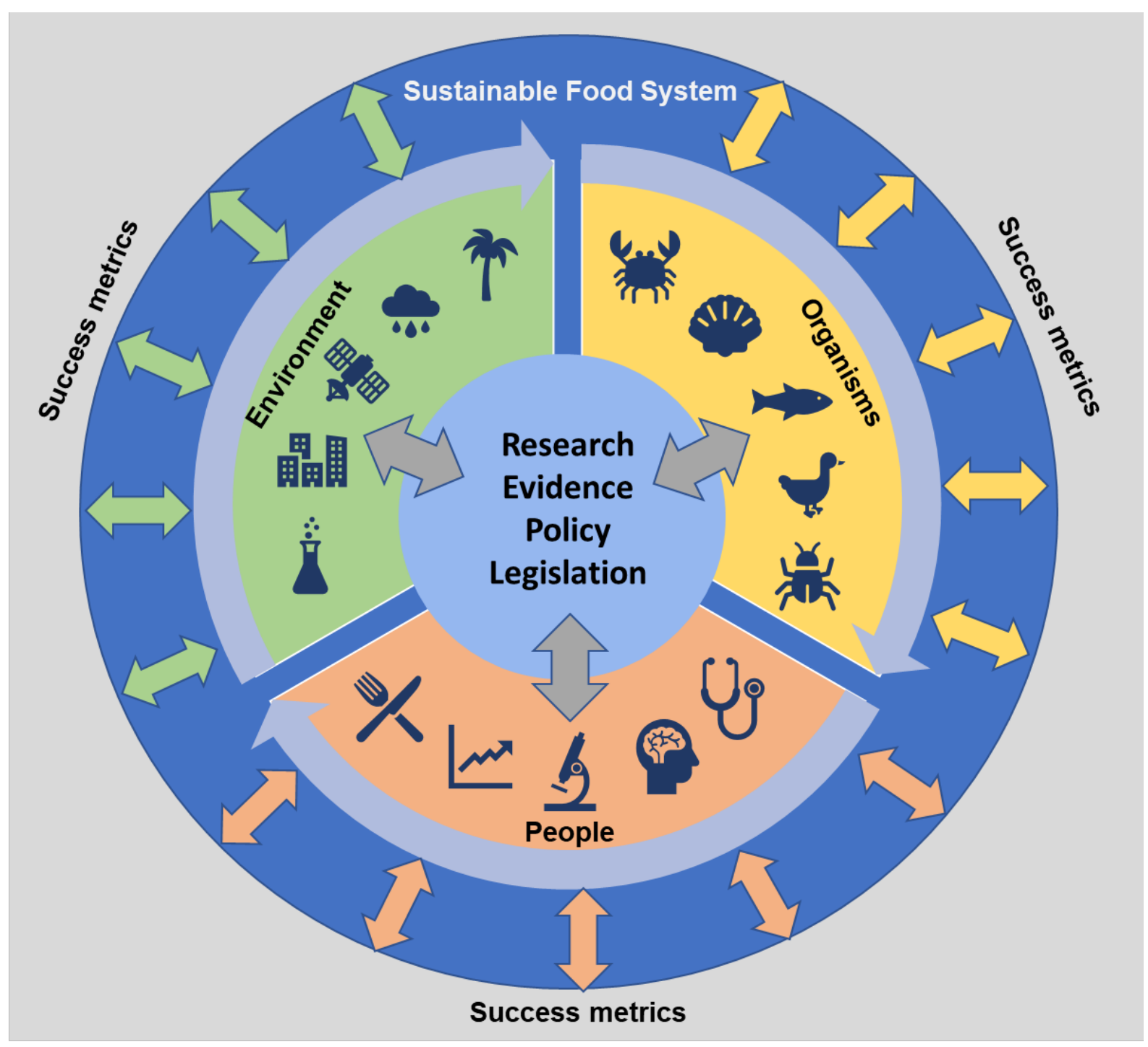

436

437

438

439

440

Figure 1. One Health approach to sustainable food system design and analysis.

Research, evidence, policy and legislation (centre) are focussed on a co-designed set of success metrics (outer circle) relating to environment, human and organism health - the interlinked components of the One Health philosophy. Using this simple framework, government, industry and society can assess specific sectors, such as aquaculture, according to principles of sustainability. Suboptimal conditions can be measured and the data used to guide research, evidence collection and policy or legislative change. Perceived benefits to human society (e.g. nutritional supply, employment, profit) are considered in the context of broader environmental cost-benefits, allowing nuanced trade-offs between success metrics in different sections of the model to be more easily identified and rebalanced using policy and legislative solutions. The systems-based approach draws upon a wider array of specialist input than may previously have been applied to sustainable food system design and is likely an efficient means of communicating food system policy to society. 


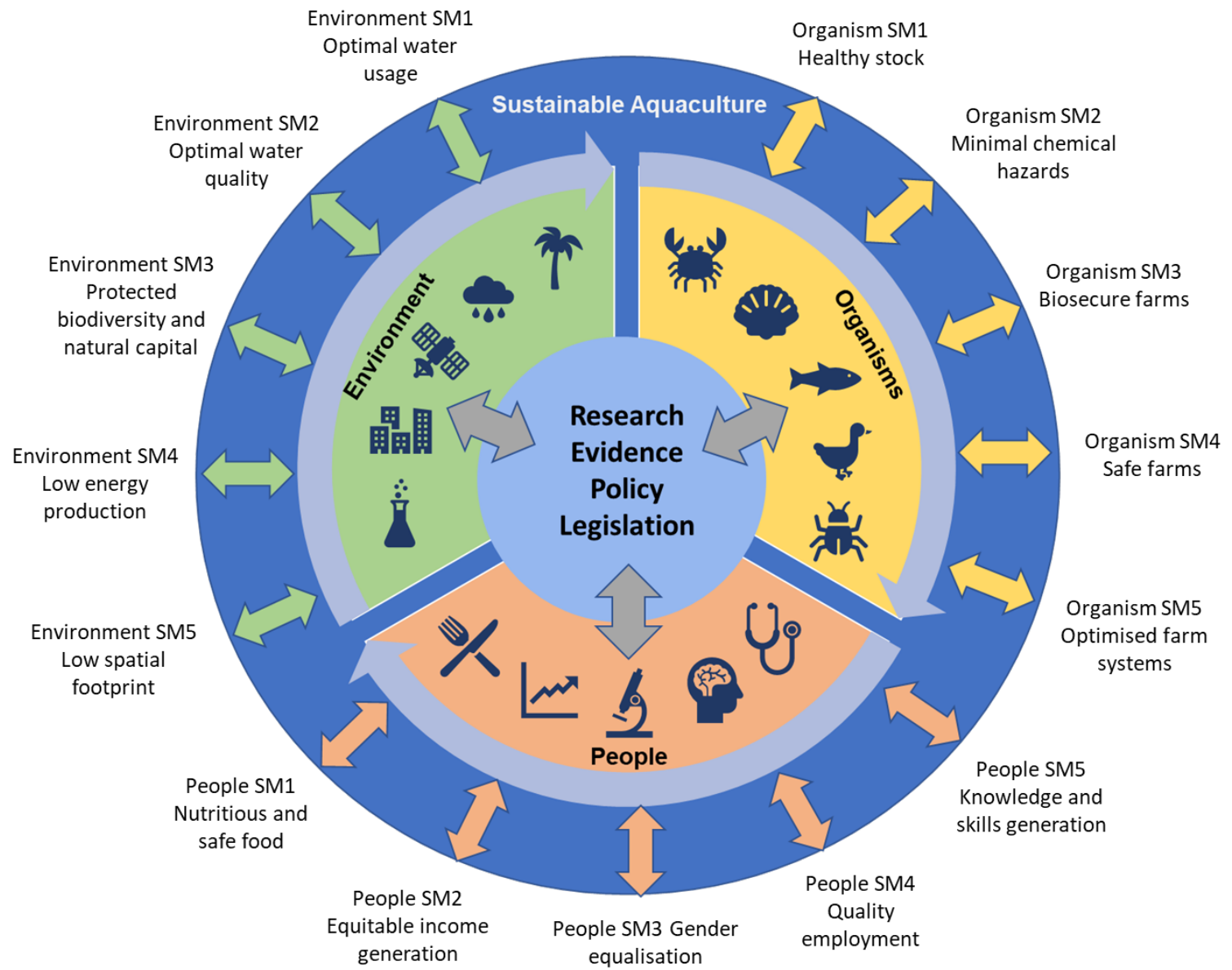

454 Figure 2. One Health success metrics for sustainable aquaculture.

A One Health approach (Figure 1) to the design and assessment of enhanced sustainable production (ESP) from aquaculture and related sub-sectors requires success metrics spanning environment, organism and human health. Descriptors for success metrics (SM) (Table 1) are applied to hypothetical sub-sectors of the aquaculture industry in Figure 3. 


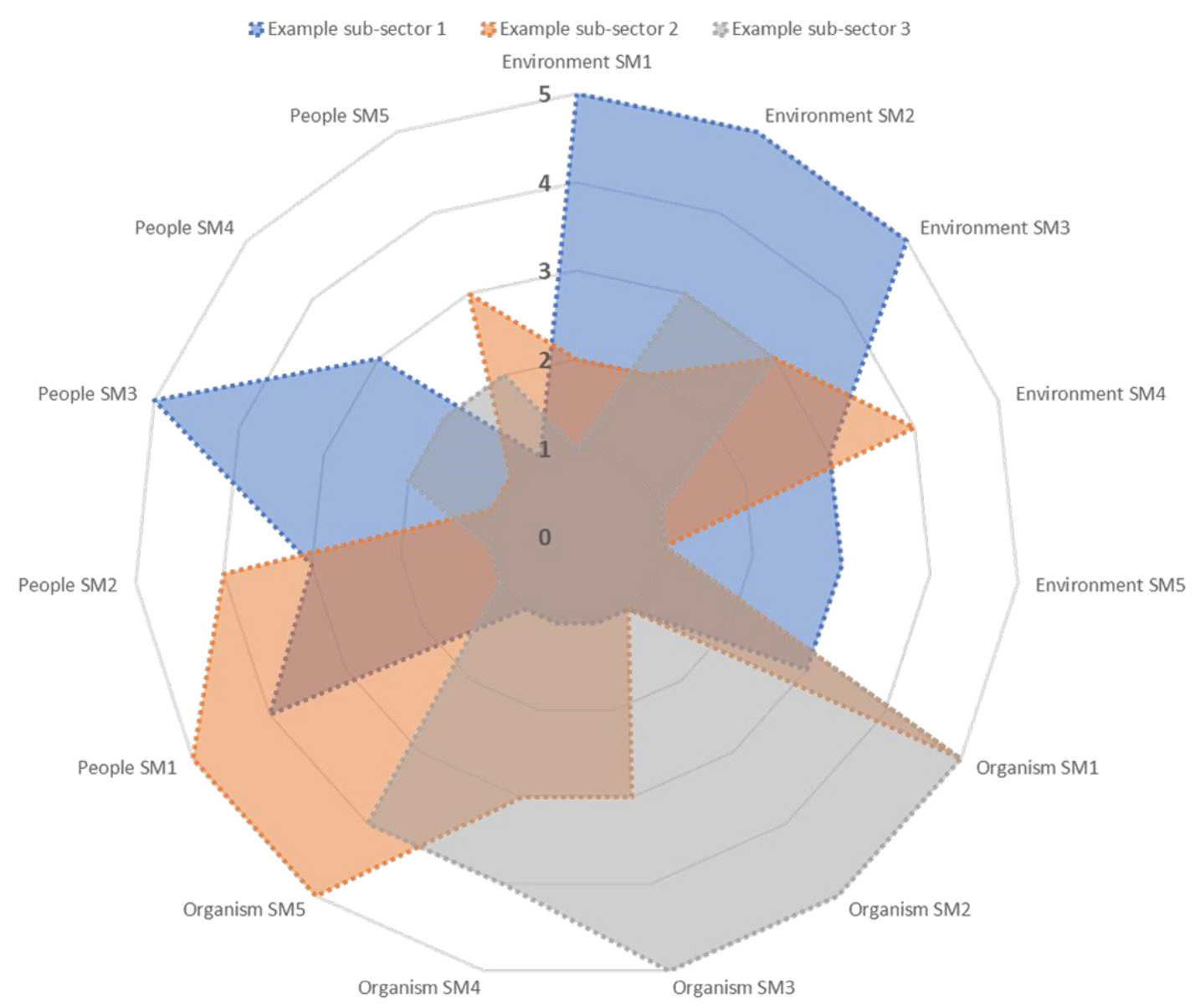

Figure 3. Application of One Health success metrics to aquaculture and related sub-sectors.

462 Demonstrable fulfilment of success metrics takes account of research and evidence available on which to base policy and legislation, and how consistency that policy and legislation is applied. When specific success metrics are being consistently fulfilled but others are performing poorly, research, evidence and policy design can be altered to support and improve poorly performing metrics. Specific success metrics (SM) for Environment, People and Organisms are provided in Table 1 and illustrated in Figure 2. Key to scale: 1 - No research, evidence, policy, or legislation is in place to allow delivery of success metric. 2 - Basic research outputs are available but have not been applied to policy formation and legislation to allow delivery of success metric consistently. 3-Applied research has been conducted and used for policy formation and legislation to deliver success metric, but not yet applied. 4 - Policy and legislation is in place, is continually refined by further research and evidence but success metric has not been consistently achieved. 5- Policy and legislation is in place and applied consistently, research and evidence contribute to further refinement, or success metric being consistently achieved. 


\begin{tabular}{|c|c|c|}
\hline One Health Success Metric & Abbreviation & Descriptor \\
\hline Nutritious and safe food & People SM1 & $\begin{array}{l}\text { The food produced from aquaculture and sub-sectors is nutritious, is an } \\
\text { acknowledged contributor to a planetary sustainable diet (Willets et al. 2019) and is } \\
\text { safe to consume, with negligible risk of exposure to harmful microbial and chemical } \\
\text { contaminants by human consumers. }\end{array}$ \\
\hline Equitable income generation & People SM2 & $\begin{array}{l}\text { The income generated from the whole industry and sub-sectors is shared equitably } \\
\text { across the stakeholder web, considers the economic risks of production, and } \\
\text { contributes to employment and development of producer communities. Income } \\
\text { generated within sector contributes directly to local poverty alleviation and wealth } \\
\text { generation. }\end{array}$ \\
\hline Gender equalisation & People SM3 & $\begin{array}{l}\text { The whole industry and sub-sectors contribute demonstrably to improving } \\
\text { opportunities for women, not only in terms of income generation and wealth } \\
\text { sharing but also in access to high quality foods and other opportunities. }\end{array}$ \\
\hline Quality employment & People SM4 & $\begin{array}{l}\text { The whole industry and sub-sectors contribute to enhanced employment } \\
\text { opportunities in direct food production and in subsidiary sectors. Employment is } \\
\text { safe, meaningful, and high quality. A sustainable production (and consumption, } \\
\text { waste) ethic is built into jobs across the whole industry, sub-sectors, and its } \\
\text { subsidiaries. }\end{array}$ \\
\hline Knowledge/skills generation & People SM5 & $\begin{array}{l}\text { Technical knowledge and skills generation relating to the whole industry and sub- } \\
\text { sectors are underpinned by continued professional development and the co- } \\
\text { ownership of a sustainability narrative by workers throughout the food web. }\end{array}$ \\
\hline Healthy stock & Organism SM1 & $\begin{array}{l}\text { High health and welfare status of stock is promoted by controlling entry of } \\
\text { pathogen and non-native species hazards, by deployment of stock management } \\
\text { procedures (e.g. genetics, stocking, and feed strategies) and promoting } \\
\text { environmental conditions conducive to low disease susceptibility in farmed stock. }\end{array}$ \\
\hline Minimal chemical hazards & Organism SM2 & $\begin{array}{l}\text { Farm management procedures which involve chemical and physical treatments are } \\
\text { carried out to impart minimal (zero) disruption on the surrounding environment } \\
\text { and native biodiversity. Measures are in place to minimise anti-microbial usage in } \\
\text { the farm environment and to negate negative impacts of anti-microbial spill over to } \\
\text { surrounding environment, wildlife, and humans. }\end{array}$ \\
\hline Biosecure farms & Organism SM3 & $\begin{array}{l}\text { High health status of wildlife is promoted by negating the risks of pathogen and NNS } \\
\text { spill-over from the farm to the surrounding environment. Trade of live animals and } \\
\text { their products take account of animal welfare, risk of pathogen and NNS transfer via } \\
\text { these movements. Biosecurity protocols followed at farm, catchment, and national } \\
\text { levels compliment those in place to control cross-boundary risks of transfer via } \\
\text { trade. }\end{array}$ \\
\hline Safe farms & Organism SM4 & $\begin{array}{l}\text { Potential for the transfer of zoonotic and environmental pathogens from stock to } \\
\text { humans is negated (including potential for transfer of AMR). The stock produced on } \\
\text { farms should be safe to handle and to eat. }\end{array}$ \\
\hline Optimised farm systems & Organism SM5 & $\begin{array}{l}\text { Farms are stocked with species appropriate to the conditions in which they are } \\
\text { being produced and in consideration of their nativity to surrounding biodiversity. } \\
\text { The genetic structure of stocks being farmed are known and taken in to account } \\
\text { relative to potential genetic spill over to native wildlife. Mixed species and } \\
\text { multitrophic systems should be considered where suitable, in attempt to optimise } \\
\text { farm systems. }\end{array}$ \\
\hline
\end{tabular}




\begin{tabular}{|l|l|l|}
\hline Optimal water usage & Environment SM1 & $\begin{array}{l}\text { Freshwater resources are used efficiently to optimally reduce any detrimental } \\
\text { effects to the functioning and productivity of natural aquatic systems, balancing use } \\
\text { of water for aquaculture with the benefits of freshwater supply for other human } \\
\text { needs. }\end{array}$ \\
\hline Optimal water quality & Environment SM2 & $\begin{array}{l}\text { Minimise (or avoid) discharges of animal pathogens, chemicals, antibiotics, excessive } \\
\text { nutrients, or other factors with potential to adversely impact the physico-chemical } \\
\text { environments on/around farms; Minimise potential for anti-microbial resistance } \\
\text { (AMR) carry-over to biodiversity }\end{array}$ \\
\hline Protected biodiversity and & Environment SM3 & $\begin{array}{l}\text { Minimise (avoid) negative impact of aquaculture on natural biodiversity. To include } \\
\text { the protection of natural (wild) genetic resources (including species grown in } \\
\text { aquaculture settings in the context of their current and future economic and } \\
\text { ecological benefits). Utilise aquaculture production to boost natural capital in } \\
\text { surrounding environments. }\end{array}$ \\
\hline Low energy production & Environment SM4 & $\begin{array}{l}\text { Aquaculture systems designed to be energy efficient with a low or negative carbon } \\
\text { cost relative to other food production systems. To include full consideration of } \\
\text { energy costs for associated with production, feed inputs, operational engineering, } \\
\text { and transport of aquaculture products for human consumption }\end{array}$ \\
\hline Low spatial footprint & Environment SM5 & $\begin{array}{l}\text { Spatial footprint of aquaculture production systems is minimised relative to yield, } \\
\text { relative to other food production systems. Location of aquaculture systems } \\
\text { promotes enhanced biodiversity and natural resource productivity (e.g. mangroves) } \\
\text { while protecting areas of cultural and heritage importance, or areas of natural } \\
\text { beauty }\end{array}$ \\
\hline
\end{tabular}




\section{1a. Where does aquaculture occur?}

Utilising data from the United Nations Food and Agriculture Organisation (FAO), The World Bank predicts that of the $106 \mathrm{mmt}$ global aquaculture output in 2016 over $95 \%$ originated from nations defined as 'Low and Middle Income' (LMIC) (https://datacatalog.worldbank.org/). Asian nations are responsible for over $90 \%$ of global yield with China consistently reported as the largest producer, with output exceeding that of all other producer nations combined. Although growth of aquaculture in China is slowing (due to factors including improved environmental legislation and an increased focus on sustainability), it's output is still expected to grow by more than $30 \%$ in the period to 2030 , easily maintaining its position as the biggest global producer over coming decades. Significant \% growth is also predicted for other producer nations over this period - most notably India, Indonesia, Vietnam, Egypt, Thailand, the Philippines and Egypt; all of which currently occupy top 10 positions in global production and predict growth of over $30 \%$ in output to 2030 (Suppl.1, Fig.1). Although current aquaculture output from Africa $(2 \mathrm{mmt})$ is relatively low compared with Asia (70mmt), significant production growth is expected in nations such as Egypt, Nigeria and Morocco, helping to double output from Africa over this period. Expansion of aquaculture in Europe is expected to grow substantially ( $\sim 30 \%$ ) between now and 2030 with relatively high production nations such as Norway showing individually similar growth potential. In the Americas, whilst significant growth is envisaged in Latin America and the Caribbean (e.g. Brazil, 89\%), growth in North America is expected to be more modest (15\%). Oceania as whole is predicted to experience significant growth, albeit from a relatively low start position in 2016, certain nations such as Australia expected to add $50 \%$ to current output (Box 1, Fig. 1). Overall, the FAO (FAO, 2018) report that these figures demonstrate how aquaculture continues to express faster growth than other major food sectors and, in many nations, a shift between predominantly capture fisheries to aquaculture is occurring. They also caution that available data likely underestimates true production given that in 2016, only 120 national data reports were available from an estimated 194 aquaculture production nations. Nevertheless, using predictions of future demand, world production of aquatic food will need to reach at least $200 \mathrm{mmt}$ by 2030 ( $18 \%$ more than 2016) with most of this expected to come from grown rather than captured sources (FAO, 2018). 


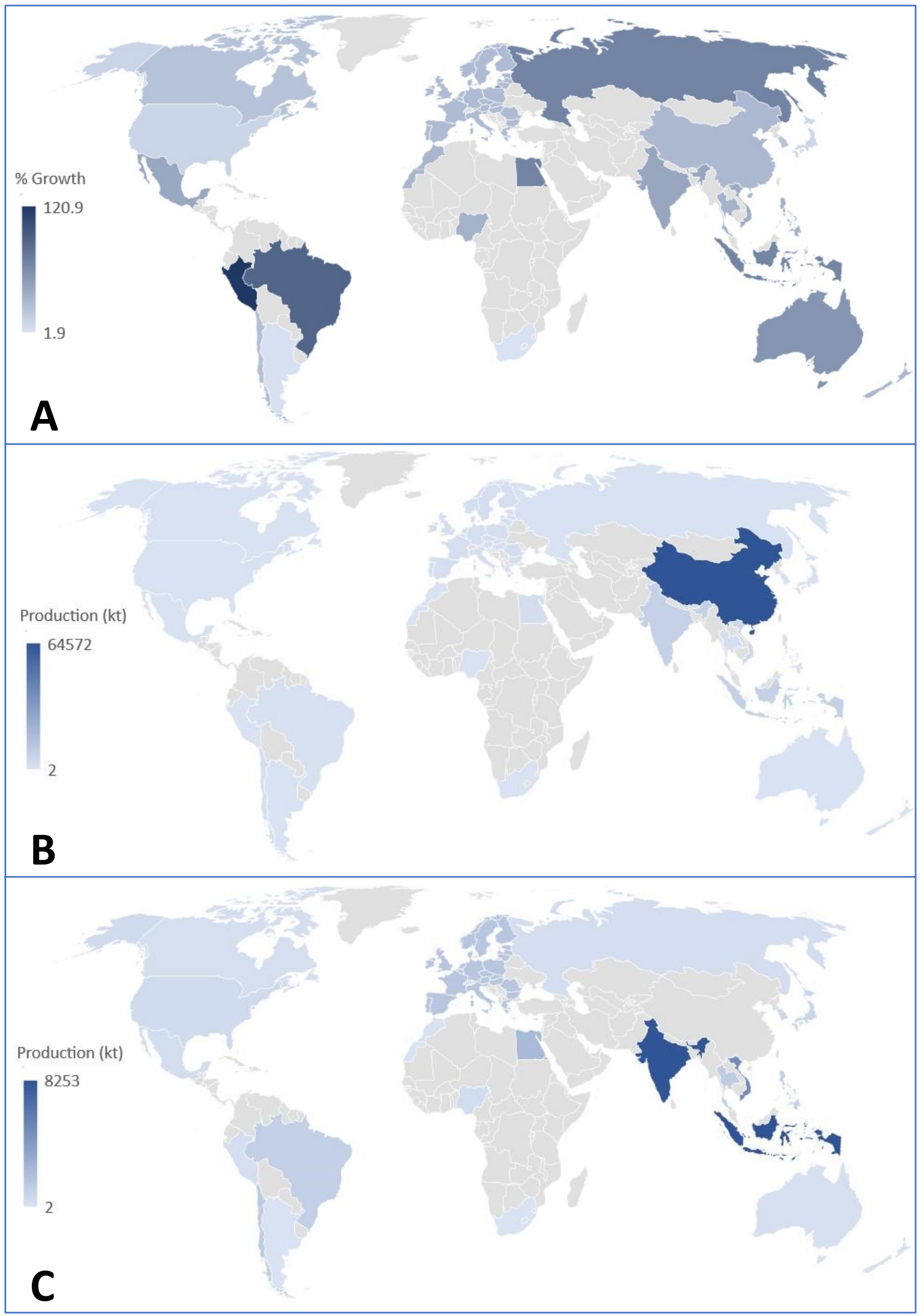

Suppl.1 Figure 1. Projected growth in aquaculture from 2016 to 2030. (A) Projected \% growth in aquaculture output by nations for period 2016 to 2030. (B). Projected production map at 2030, China data included. (C) Projected production map at 2030, China data excluded. Key: according to medium term predictions using the FAO fish model (see p. 182 of FAO, 2018). All European Union Member State data represented en bloc (and including the UK). Over $87 \%$ of the increase in projected aquaculture production to 2030 will come from countries in Asia with China remaining the dominant producer, albeit with a slight decrease in global share from $62 \%$ in 2016 to $59 \%$ in 2030 (FAO, 2018). Data not available for all producer nations. 


\section{SUPPLEMENT 1 (CONT.)}

\section{1b. What does aquaculture produce?}

Aquaculture is a $\$ 245 \mathrm{bn}$ industry producing over 100 million metric $(\mathrm{mmt})$ tonnes of food in almost all types of aquatic biome. Despite perceptions of aquaculture as an industry of intensive production of familiar species such as Atlantic salmon (Salmo salar), it instead encapsulates an incredibly diverse business producing almost 600 different species of finfish, mollusc, crustacean, amphibian, invertebrate and algae which underpin one of the fastest growing and highly traded food sectors on the planet. The industry is of course dominated by some key species. For finfish, carps comprise almost $30 \%$ of global production, with tilapia (8\%), salmon (4\%) and catfish (3\%) - an important point here that the majority of global aquaculture occurs in inland (fresh) waters, currently producing over $60 \%$ of all finfish produced and eaten. This predominance in freshwaters also reveals the relative artisanal nature of production in many areas; earthen ponds, increasingly in combined rice-fish production supporting wealth generation and poverty alleviation in rural communities. Around $30 \mathrm{mmt}$ of production occurs in marine and coastal waters. Here, molluscan shellfish production predominates $(17 \mathrm{mmt})$ with oysters $(30 \%)$, Manila clam $(25 \%)$ and scallops $(11 \%)$ comprising most of the production. Crustacean aquaculture $(5 \mathrm{mmt})$, well over half of which is focussed on a single species, the Pacific whiteleg shrimp (Penaeus vannamei) occurs mostly in marine and brackish waters, creating high value export commodity for low- and middle-income nations (Suppl.1 Figure 2). Other crustaceans such as crayfish (12\%) and Chinese mitten crabs (10\%) are important national food commodities in Asia, mainly farmed in freshwaters. Other marine and freshwater animal species considered within the banner of aquaculture include Chinese softshell turtles (350,000t per annum production), sea cucumbers (200,000t per annum) and frogs $(100,000 \mathrm{t}$ per annum). Finally, seaweed production comprises one of the fastest growing sub-sectors of aquaculture, with $30 \mathrm{mmt}$ produced in 2016 . The industry is dominated by tropical species such as Eucheuma and Kappaphycus spp. (>30\% of all production), kelps (30\%) and red algae of the genus Gracilaria (15\%). Seaweeds either enter directly into human consumption or, are processed for valuable by-products such a carrageenan, agar or other nutritional supplements. The diversity of aquaculture represented above reflects not only the array of habitats in which aquaculture occurs but also the different feeding requirements of those species produced. Currently, around half of all aquaculture production globally is classified as 'extractive' - that is either growing on organic matter present within natural waters (e.g. bivalve molluscs) or utilising photosynthesis and presence of nutrients to grow (i.e. seaweeds). It should be noted that some finfish aquaculture is also extractive (e.g. filter-feeding carp). The co-culture of species, a process often termed integrated multi-trophic aquaculture offers potential to mitigate waste streams from fed species with such extractive species. The summary above was produced with significant reference to the FAO 'State of World Fisheries and Aquaculture 2018' report [1].

\section{References}

[1] FAO. The State of World Fisheries and Aquaculture 2018 - Meeting the sustainable development goals. Food and Agriculture Organization of the UN (FAO), Rome, Italy. Licence: CC BY-NC-SA 3.0 IGO (2018). 


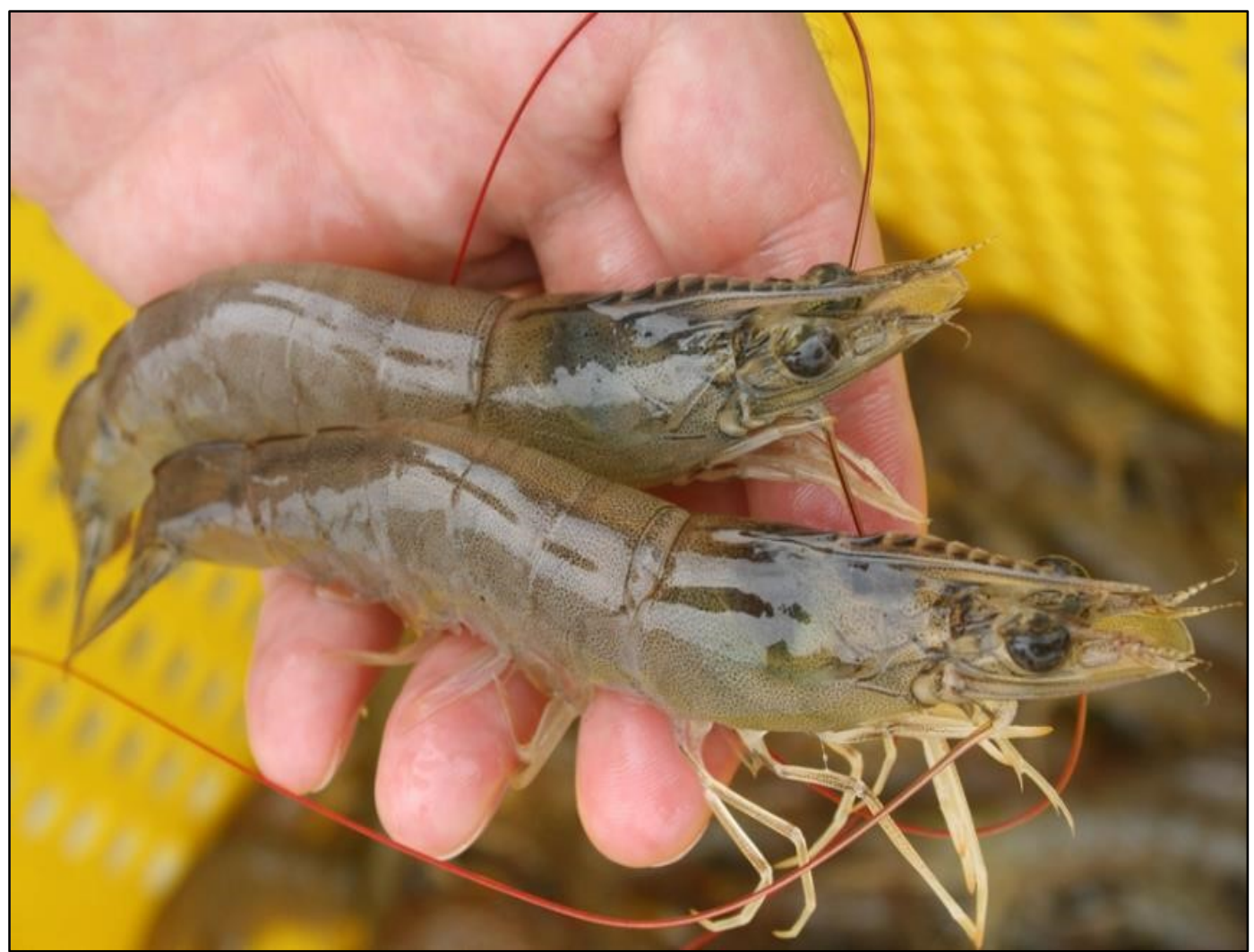

Suppl.1 Figure 2. Crustacean aquaculture, a $\$ 20 \mathrm{bn}$ global industry generating over $5 \mathrm{mmt}$ of product is dominated by a single shrimp species, the Pacific whiteleg shrimp (Penaeus vannamei), farmed in over 40 countries (mostly outside of its native range on the Pacific coast of Central and South America) and generating first sale earnings in excess of $\$ 15 \mathrm{bn}$ annually. Despite generation of significant export income for producer nations in low- and middle-income nations, farming of penaeids shrimp has been criticised for its role in vulnerable habitat loss, wild harvesting of broodstock, overuse of antibiotics and enforced human labour in some regions. 


\section{SUPPLEMENT 2}

\section{One Health}

One Health has numerous definitions but broadly is the collaborative, multi-sectoral, and transdisciplinary approach to achieving beneficial health and well-being outcomes for people, nonhuman organisms and their shared environment, recognizing the inextricable interconnection between the health of each (One Health Commission; www.onehealthcommission.org). The politicization of One Health as a principle for health management arguably originates from several early $21^{\text {st }}$ Century events in which institutions responsible for global animal and human health respectively, formally recognized the links between their sectors and, the importance of establishing collaborative approaches to managing zoonotics and, pandemic spread of disease [1]. However, perceptions of the consequences of the interactions between the environment, animals and humans have much earlier origins, and continue to shape the evolution of human societies in relation to the organisms with which they interact and, the environments that they co-inhabit [2]. For these reasons, modern definitions of One Health as a principle by which animal, human and environmental health outcomes are understood (and managed) must extend well beyond zoonotics to one in which human health per se is considered a direct consequence of the health status of the environment from which the resources needed to sustain the population are drawn. In this way, One Health (which as Hinchliffe, 2015 proposes, has a certain matter of fact-ness and common sense associated with its discourse [3]) may become established as a political, scientific and societal movement reaching far beyond medical and veterinary professionals - underpinning an approach by which major life support systems (including food production) can be designed or assessed and, against which, scientific evidence can be gathered and policy and legislation applied. An extension of the application of One Health principles beyond that of specific animal/human health diseases to other grand challenges (e.g. obesity, food security and green urbanisation) offers an inclusive means by which wider communities can engage, and operational plans can be designed. Recent works, such as those of the Network for Evaluation of One Health are helping to frame this wider application and, to provide examples where One Health principles are being put in to place to tackle broad societal challenges [4].

\section{References}

[1] Gibbs, E.P.J. (2014). The evolution of One Health: a decade of progress and challenges for the future. Veterinary Record doi: 10.1136/vr.g143

[2] Evans, B.R., Leighton, F.A. (2014). A history of One Health. Rev. sci. tech. Off. int. Epiz., 33, 413420

[3] Hinchliffe, S. (2015). More than one world, more than one health: Re-configuring interspecies health. Social Science \& Medicine 129, 28-35

[4] Rüegg, S., Häsler, B., Zinsstag, J. (2018). Integrated approaches to health: A handbook for the evaluation of One Health. Wageningen Academic Publishers, The Netherlands. ISBN: 978-908686324-2. DOI: 10.3920/978-90-8686-875-9. 255 pp. 